RESEARCH ARTICLE

\title{
A Study on the Relationship of Profile Characteristics with Group Performance of Tribal Farmer Interest Groups (FIGs)
}

Mathuabirami V* and Dr. S Kalaivani

Department of Agricultural Extension and Rural Sociology, Tamil Nadu Agricultural University, Coimbatore - 641003

\begin{abstract}
The present study aimed to analyze the relationship of profile characteristics with group performance of tribal FIGs. The survey was purposively conducted in Erode district as it contains more number of tribal Farmer Interest Groups (FIGs). A total of five Tribal FIGs were randomly selected from 16 Tribal FIGs belonging to Dhimbam Dhaniya Farmer Producer Company Limited (DDFPCL) and the total sample size was 100. A well-structured interview schedule was prepared and employed to collect the data from the respondents. The findings showed that majority of the respondents were young aged with high school education, female marginal farmers receiving low level of annual income with medium level of farming experience. They had also received medium level of support from institution. The findings of the study also revealed that majority of the members of tribal FIGs had 76.00, 75.00, 73.00, 67.00 and 55.00 percentages of self-confidence, economic motivation, group leadership, group communication and information seeking behaviour respectively.To improve the performance of tribal FIGs, measures should be taken to increase the level of group communication, group leadership and group cohesiveness. This can be increased through organizing regular meetings for members, proper selection of leaders and making the members to understand the importance of group action.
\end{abstract}

Keywords: Farmers Interest Groups (FIGs); Group performance; Correlation; Multiple regression.

\section{INTRODUCTION}

Small and marginal farmers are the primary contributors to agricultural production in India and thus, $85 \%$ of farmers possessed less than or about two hectares (Sharma et al. (2011)). The productivity of small and marginal farmers is superior to that of medium and big farmers, but their economic condition is also worse. They face problems such as poor bargaining power, lack of technical services and insufficient research - extension - farmer linkages and also poor implementation of improved technologies and innovations. Approaches akin to collective action through co-operatives and farmer organizations had been introduced to perk up the scenario of small farmers (Shepherd (2007)). Self Help Groups (SHGs,) FIGs, co-operatives producers associations, marketing associations etc. had bestowed in maximizing the input-output ratio and finally increasing the profit of producers. Farmer's confidence level was increased through the establishment of Farmers Interest Groups (FIGs) (Singh and Srinivasan (1998)). A Farmer Interest Group (FIG) is a self-managed, independent group of farmers with a shared goal and interest (Department of Agriculture \& Cooperation (2013).
FIG approach is a - business oriented approach that insists on money to money, i.e., enabling farmers to market their produce directly through formation of Farmer Producer Organizations (Mathuabirami et al. 2020). Patil et al. (2014) had analyzed the impact of collective action of farmers through FIG (Farmer Interest Group) and found that there was a reduction in the cost of cultivation by sharing inputs and gained additional returns FIG is an innovative approach with an idea to develop the value chain for the produce, establish brand value and link the farmers with market and consumers. It was promoted with a purpose of collectivizing production especially at small holder level and empower them for better bargaining power. Tribal communities were blessed with ample of opportunities like honey, bee wax, resins, wood oil, etc. for improving their livelihood. These products had good market value, but tribal people were not getting profit because of lack of marketing knowledge. As a result majority of areas of tribes overlapped with country's major forest areas which show highest area of poverty. Tribal farmers were transformed to wage laborers, thus contributing between 70 to $80 \%$ of the total labor. In spite of favorable resource conditions, tribal regions perform poorly in terms of infrastructure, returns

$$
107 \mid 10-12 \text { | } 1
$$


from agriculture and almost all human development indicators, Catalyst Management Service (2009). They were facing problems in getting quality inputs for agriculture and good price for their produce. The challenges faced by the small and marginal farmers are being attempted to solve through the concept of group approach that empowers them by economies of scale and access to information, agricultural services, technology, etc. Tribal FIGs may play a unique role in improving the economic status of tribal people through which they can access to credit, market facilities and value-added forest produce (Mathuabirami and Kalaivani, 2020). Thus effective functioning of tribal FIGs is very essential. Therefore analyzing performance of existing tribal FIGs may help to formulate a strategy to improve the livelihood of tribal farmer through collective action. Hence the study has been attempted with the objectives of studying the profile characteristics of the members of tribal FIGs and the relationship of group performance of Tribal FIGs with profile characteristics.

\section{MATERIAL AND METHODS}

The research design adopted for this study is an ex-post-facto design. Erode district was purposively selected for conducting the study. MYRADA (Mysore Resettlement and Development Agency) KVK has been assigned as a resource agency for the promotion of one FPO in Erode district of Tamil Nadu supported under Tamil Nadu Small Farmers Agribusiness Consortium(TNSFAC) to increase the income level of the farmers by building, knowledge and facilitating supply inputs and linking to markets for produces. MYRADA KVK had planned to establish FPO through promoting Farmer Interest Groups (FIGs) concept among tribes. Dimbam Dhaniya Farmer Producer Company Limited (DDFPCL) comprises of 62 FIGs covering 27 villages. FIGs were federated into DDFPCL. Out of these 27 villages, nine villages were dominated by tribes, namely Chilumaiedoddi, Devarnatham, Pudhukadu, Guliyada, Sujjalakare, Kottamalam, Bejjalatti, Galidimbam and Ittarai. Total

$$
\text { Group Performance of Tribal FIGs }
$$

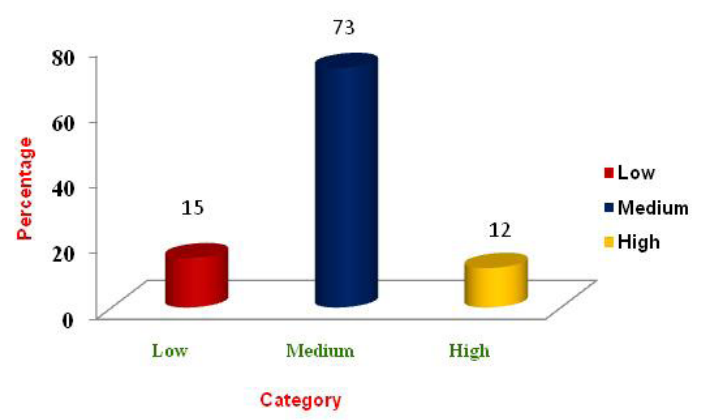

Figure 1. Distribution of respondents based on group performance of Tribal FIGs. of four Tribal FIGs were randomly selected from 16 Tribal FIGs belonging to DhimbamDhaniya Farmer Producer Company Limited (DDFPCL) which had resulted in a sample size of 100 by employed whole sampling method. The details of selected FIGs is furnished in Table 1.

\section{Table 1: Details of selected Tribal FIGs:}

\begin{tabular}{cclc}
\hline S.No. & $\begin{array}{c}\text { Name of the } \\
\text { Village }\end{array}$ & Name of the FIG & $\begin{array}{c}\text { No. of } \\
\text { members }\end{array}$ \\
\hline 1. & Guliyada & $\begin{array}{l}\text { Kadehatti } \\
\text { Muniyappan FIG }\end{array}$ & 15 \\
2. & & $\begin{array}{l}\text { Periyasamyaiyyan } \\
\text { FIG }\end{array}$ & 16 \\
3. & Sujjalakare & $\begin{array}{l}\text { Sri Karppusamy } \\
\text { FIG }\end{array}$ & 25 \\
4. & Kottamalam & $\begin{array}{l}\text { Sri Magaliamman } \\
\text { FIG }\end{array}$ & 24 \\
5. & Ittari & Ilandhalir FIG & 20 \\
& & Total & $\mathbf{1 0 0}$ \\
\hline
\end{tabular}

A well-structured interview schedule was prepared to collect the data. Correlation and multiple regression analyses and were carried out to study the relationship of selected independent variables with the dependent variable effectiveness of tribal FIGs.

\section{RESULTS AND DISCUSSION}

\section{Profile characteristics of the members of tribal FIGs}

In social science, it is essential to analyze the profile of farmers, which would give a basic and clear understanding of the background of the farmers. This would help in interpreting the data gathered in an effective way. Profile characteristics of the members of tribal FIGs were studied through sixteen variables such as age, gender, educational status, annual income, farm size, farming experience, institutional support, training has undergone, economic motivation, information-seeking behavior, group communication, group leadership, group cohesiveness, decision-making pattern, selfconfidence and self-reliance. The data pertaining to the profile characteristics of the respondents were collected, analyzed and presented in Table 2.

From Table 2 it could be seen that exactly half of the members of tribal FIGs (50.00\%) were young who had readily come forward to become the member of FIG followed by more than one third of them (36.00\%) who were middle-aged and about one fifth (14\%) were old. Old aged tribes hesitated to become the member of FIG. And also, about three-fifth of the members of tribal FIGs (61\%) were female followed by $39 \%$ male. Hence more women FIGs were formed compared to men FIGs. These FIGs were mainly formed for promoting entrepreneurial activities for

107|10-12 | 2 
non-working women. The findings of the study are in congruence with the findings of Jona and Nghixulifwa (2018). It could also be seen that about one-fourth of the respondents (24\%) had high school education, followed by $19.00,14.00$ and 11.00 percentages at higher secondary, middle education and each at collegiate and primary education levels respectively.

Table 2 Distribution of respondents based on the profile characteriscts of the members of tribal FIGs.

$n=100$

\begin{tabular}{|c|c|c|c|c|}
\hline \multirow[t]{2}{*}{ S.No. } & \multirow[t]{2}{*}{ Profile Characteristics } & \multirow[t]{2}{*}{ Category } & \multicolumn{2}{|c|}{ Respondents } \\
\hline & & & No. & Per cent \\
\hline \multirow{5}{*}{1.} & \multirow{4}{*}{ Age } & Young & 50 & 50.00 \\
\hline & & Middle & 36 & 36.00 \\
\hline & & Old & 14 & 14.00 \\
\hline & & Total & 100 & 100.00 \\
\hline & \multirow{3}{*}{ Gender } & Male & 39 & 39.00 \\
\hline \multirow[t]{2}{*}{2.} & & Female & 61 & 61.00 \\
\hline & & Total & 100 & 100.00 \\
\hline \multirow{8}{*}{3.} & \multirow{8}{*}{ Educational status } & Illiterate & 10 & 10.00 \\
\hline & & Functionally literate & 8 & 8.00 \\
\hline & & Primary education & 11 & 11.00 \\
\hline & & Middle school education & 14 & 14.00 \\
\hline & & High school education & 24 & 24.00 \\
\hline & & Higher Secondary education & 19 & 19.00 \\
\hline & & Collegiate education & 14 & 14.00 \\
\hline & & Total & 100 & 100.00 \\
\hline \multirow{4}{*}{4.} & \multirow{4}{*}{ Annual income } & Low & 38 & 38.00 \\
\hline & & Medium & 36 & 36.00 \\
\hline & & High & 26 & 26.00 \\
\hline & & Total & 100 & 100.00 \\
\hline \multirow{4}{*}{5} & \multirow{4}{*}{ Farm size } & Marginal farmer & 65 & 65.00 \\
\hline & & Small farmer & 30 & 30.00 \\
\hline & & Big farmer & 5 & 5.00 \\
\hline & & Total & 100 & 100.00 \\
\hline \multirow{4}{*}{6.} & \multirow{4}{*}{ Farming experience } & Low & 29 & 29.00 \\
\hline & & Medium & 53 & 53.00 \\
\hline & & High & 18 & 18.00 \\
\hline & & Total & 100 & 100.00 \\
\hline \multirow{4}{*}{7.} & \multirow{4}{*}{ Institutional support } & Low & 10 & 10.00 \\
\hline & & Medium & 83 & 83.00 \\
\hline & & High & 7 & 7.00 \\
\hline & & Total & 100 & 100.00 \\
\hline \multirow{4}{*}{8.} & \multirow{4}{*}{ Training undergone } & None & 45 & 45.00 \\
\hline & & Attended one training & 18 & 18.00 \\
\hline & & Attended more than one training & 37 & 37.00 \\
\hline & & Total & 100 & 100.00 \\
\hline \multirow{4}{*}{9.} & \multirow{4}{*}{ Economic motivation } & Low & 18 & 18.00 \\
\hline & & Medium & 75 & 75.00 \\
\hline & & High & 7 & 7.00 \\
\hline & & Total & 100 & 100.00 \\
\hline \multirow{4}{*}{10.} & \multirow{4}{*}{ Information seeking behaviour } & Low & 24 & 24.00 \\
\hline & & Medium & 55 & 55.00 \\
\hline & & High & 21 & 21.00 \\
\hline & & Total & 100 & 100.00 \\
\hline
\end{tabular}

$107|10-12| 3$ 


\begin{tabular}{|c|c|c|c|c|}
\hline \multirow{4}{*}{11.} & \multirow{4}{*}{ Group communiation } & Low & 8 & 8.00 \\
\hline & & Medium & 67 & 67.00 \\
\hline & & High & 25 & 25.00 \\
\hline & & Total & 100 & 100.00 \\
\hline \multirow{4}{*}{12.} & \multirow{4}{*}{ Group leadership } & Low & 15 & 15.00 \\
\hline & & Medium & 73 & 73.00 \\
\hline & & High & 12 & 12.00 \\
\hline & & Total & 100 & 100.00 \\
\hline \multirow{4}{*}{13.} & \multirow{4}{*}{ Group cohesiveness } & Low & 21 & 21.00 \\
\hline & & Medium & 65 & 65.00 \\
\hline & & High & 14 & 14.00 \\
\hline & & Total & 100 & 100.00 \\
\hline \multirow{4}{*}{14.} & \multirow{4}{*}{ Decision making pattern } & Low & 14 & 14.00 \\
\hline & & Medium & 63 & 63.00 \\
\hline & & High & 23 & 23.00 \\
\hline & & Total & 100 & 100.00 \\
\hline \multirow{4}{*}{15.} & \multirow{4}{*}{ Self Confidence } & Low & 16 & 16.00 \\
\hline & & Medium & 76 & 76.00 \\
\hline & & High & 8 & 8.00 \\
\hline & & Total & 100 & 100.00 \\
\hline \multirow{4}{*}{16.} & \multirow{4}{*}{ Self Reliance } & Low & 29 & 29.00 \\
\hline & & Medium & 46 & 46.00 \\
\hline & & High & 25 & 25.00 \\
\hline & & Total & 100 & 100.00 \\
\hline
\end{tabular}

Also, it was found that 8.00 and $10 \%$ of the respondents were functionally literate and illiterate, respectively. It was observed that less than forty per cent of the members of tribal FIGs were found at low (38.00\%) and medium (36.00\%) levels of income because most of the tribal farmers of the sample belonged to marginal farmer category. Remaining 26.00 per cent of the members of tribal FIGs were found at high-income level. The findings of the present study are in line with the findings of Chandravadia et al. (2018). It could also be observed in Table 2 that three-fifths of the respondents (65.00\%) were marginal farmers, followed by 30 and $5 \%$ as small and big farmers. The results clearly indicate that vast majority of the respondents (95.00\%) were under marginal to small farmer categories because of land disintegration. The findings of the study were similar to the findings of Satish et al. (2018) and Pandey and De (2015). It could also be seen that little more than half of the respondents $(53.00 \%)$ had medium years of experience in farming, followed by 29.00 and 18.00 percentages with low and high levels of experience in farming. This may be due to the fact that majority of the respondents (86\%) were young and middle-aged. Similar findings were reported by Mooventhan et al. (2015) and Satish et al., (2018). It could be seen that majority of the respondents (83.00\%) had received medium level of institutional support, followed by 10 and $7 \%$ at low and high levels of institutional support, respectively. Because of remoteness, they were receiving medium level of institutional support. They were receiving institutional support from institutions such as MYRADA KVK, State Department of Agriculture and Forest Department. These institutions were giving technical guidance from production to marketing of crops and value addition of Non-wood Forest Produces. The members of FIGs were well informed about various schemes of tribal welfare and also they were receiving credit support during needy situations. It can be inferred from the results that about half of the respondents (45.00\%) had not attended any training programme for the past one year because most of the programmes were conducted for leaders along with two or three progressive farmers of the FIG and also conducted in distant places.

\section{Table 3: Group Performance of Tribal FIG}

\begin{tabular}{clcc}
\hline S.No. & Category & No. & Per cent \\
\hline 1. & Low & 15 & 15.00 \\
2. & Medium & 73 & 73.00 \\
3. & High & 12 & 12.00 \\
& Total & $\mathbf{1 0 0}$ & $\mathbf{1 0 0 . 0 0}$ \\
\hline
\end{tabular}

Also, it was found that more than one-third of the respondents $(37.00 \%)$ had attended more than one training and the remaining 18.00 per cent of the respondents had attended only one training

$107|10-12| 4$ 
programme. The results further interpret that $93 \%$ of the members of tribal FIGs had low to medium level of economic motivation and rest of the members of tribal FIGs (18\%) had high level of economic motivation. This may be due to the reason that most of the members of tribal FIGs neither want to be too poor or too rich. It was witnessed from Table 2 that about half of the respondents (55\%) had medium level of information-seeking behavior followed by about one-fourth of the respondents (24\%) at low level and $21 \%$ at high level of informationseeking behavior. It could be interpreted that $76 \%$ of the respondents had medium to high level of information seeking behavior. This is because of the interest of respondents towards farming and to know about the improved technologies. More than sixty-five per cent of the respondents $(67.00 \%)$ had medium level of group communication followed by 25 and 8 percentages at high and low levels of group communication, respectively. It is mandated for the members of tribal FIGs to attend group meetings; otherwise, they had to pay fine. Almost all the members had attended the group meetings and they used to communicate with each other on the day of the meeting. It could also be found that three fifth of the members of tribal FIGs (65.00\%) had medium level of group cohesiveness, followed by 21 per cent and 14.00 per cent at low and high levels of group cohesiveness, respectively. It could be seen from table 2 that three fifths of the members of tribal FIGs (63\%) belonged to the medium level of decision-making pattern followed by $23 \%$ and $14 \%$ at high and low levels, respectively. The present findings are similar to the findings of Pandey et al. (2015). Also, a little more than three fourth of the members of tribal FIGs (76.00\%) had medium level of self-confidence followed by 16.00 and 8.00 percentages at low and high levels, respectively. It is clearly evident from Table 2 that nearly half of the members of tribal FIGs (46.00\%) had opined that they have medium level of self-reliance followed by 29.00 and 25.00 percentages at low and high levels of self-reliance.

Table 4: Simple Correlation coefficient and Multiple regression analysis of profile characteristics towards the group performance tribal FIGs.

\begin{tabular}{|c|c|c|c|c|}
\hline S.No. & Variables & $\begin{array}{c}\text { Correlation coefficient } \\
\text { ('r' values) }\end{array}$ & $\begin{array}{l}\text { Regression Co } \\
\text { efficient }\end{array}$ & 't' values \\
\hline 1. & Age (X1) & $0.150 N S$ & 2.420 & $2.004 *$ \\
\hline 2. & Gender (X2) & $0.023 N S$ & 0.901 & $0.681 \mathrm{NS}$ \\
\hline 3. & Educational status (X3) & $-0.095 \mathrm{NS}$ & 0.229 & $0.537 \mathrm{NS}$ \\
\hline 4. & Annual Income (X4) & $0.055 N S$ & 1.845 & $1.640 \mathrm{NS}$ \\
\hline 5. & Farm Size (X5) & $0.247 *$ & 2.499 & $2.018 *$ \\
\hline 6. & Farming experience (X6) & $0.071 \mathrm{NS}$ & 2.802 & $2.060 *$ \\
\hline 7. & Institutional support (X7) & $-0.067 \mathrm{NS}$ & -0.544 & $-0.305 N S$ \\
\hline 8. & Training undergone (X8) & $0.025 N S$ & -0.947 & $-1.244 \mathrm{NS}$ \\
\hline 9. & Economic motivation (X9) & $0.338 * *$ & -0.828 & $-0.388 \mathrm{NS}$ \\
\hline 10. & Information seeking behavior (X10) & $-0.394 * *$ & -3.491 & $-2.305 *$ \\
\hline 11. & Group communication (X11) & $0.561 * *$ & 4.241 & $2.415 * *$ \\
\hline 12. & Group leadership (X12) & $0.204 *$ & 6.146 & $3.579 * *$ \\
\hline 13. & Group cohesivenss (X13) & $0.367 * *$ & -1.315 & $-0.895 N S$ \\
\hline 14. & Decision making pattern (X14) & $-0.233^{*}$ & -2.124 & $-1.087 N S$ \\
\hline 15. & Self confidence (X15) & $-0.065 \mathrm{NS}$ & -0.211 & $-0.168 \mathrm{NS}$ \\
\hline 16. & Self reliance (X16) & $-0.175 N S$ & -1.546 & $-1.626 \mathrm{NS}$ \\
\hline \multicolumn{2}{|c|}{$\mathrm{R} 2=0.524$} & \multicolumn{3}{|c|}{$* *=$ significant at $1 \%$ level } \\
\hline \multicolumn{2}{|c|}{$F=5.7$} & \multicolumn{3}{|c|}{ * = significant at $5 \%$ level } \\
\hline
\end{tabular}

\section{Group Performance of tribal FIGs}

The group performance was carefully investigated through the social interaction process, namely cooperation, competition, conflict, accommodation and assimilation. This helped to understand how the social interaction process would contribute to the overall group performance of Tribal FIG. The distribution of respondents according to the Group 
Performance of Tribal FIGs is furnished in Table 3 and Fig. 1.

It is clear from Table 3 that nearly three fourth of the members (73\%) admitted that the tribal FIGs had medium level of group performance, followed by about 15 and $12 \%$ of the members at low and high levels of group performance, respectively. This result is due to the culture, lack of involvement and participation, domination by few individuals that had inhibited the performance of tribal FIGs. The present findings are in line with Naveenkumar and Radhakrishnan (2017).

\section{Relationship of profile characteristics with group performance of tribal FIGs.}

In order to find out the relationship between profile characteristics of the respondents and their group performance of Tribal FIGs, correlation and multiple regression analyses were worked out and the details are given in Table 4.

It could be inferred from Table 4 that out of 16 independent variables, three variables namely economic motivation (X9), group communication (X11) and group cohesiveness (X13) were positively and significantly associated with group performance of tribal FIGs at one per cent probability level and two independent variables viz. farm size (X5) and group leadership (X12) had positive and significant association with group performance of tribal FIGs at five per cent level of significance. From this study, it was justified that group-related variables such as group communication, group leadership and group cohesiveness were main components for group performance of tribal FIGs. Also, it could be seen that economically motivated individuals are readily involved in group activities and contributed to high level of group performance.

The results also showed that information-seeking behavior (X10) and decision-making pattern (X14) were negatively and significantly associated with group performance of Tribal FIGs at one per cent and five per cent levels of probability, respectively. It could also be seen from Table 4 that other variables viz., age $(X 1)$, gender $(X 2)$, educational status (X3), annual income (X4), farming experience (X6), Institutional support (X7), training undergone (X8), self-confidence (X15) and Self-reliance (X16) had shown non- significant relationship with group performance of tribal FIGs.

The extent of contribution of profile characteristics with the group performance of tribal FIGs was further worked out through multiple regression analysis and the results are presented in Table 4.

Multiple regression analysis was carried out to study the strength of the relationship between the independent variables and the dependent variable, group performance of tribal FIGs. It could be seen from Table 4 that the $R 2$ value was 0.524 which revealed that the sixteen independent variables taken together explained for 52.4 per cent of the variation in the dependent variable viz., group performance of tribal FIGs. The ' $F$ ' value of 5.7 was significant at $1 \%$ level of probability. Since the ' $F$ ' value was significant, the prediction equation was fitted for the group performance of tribal FIGs and the same is given here.

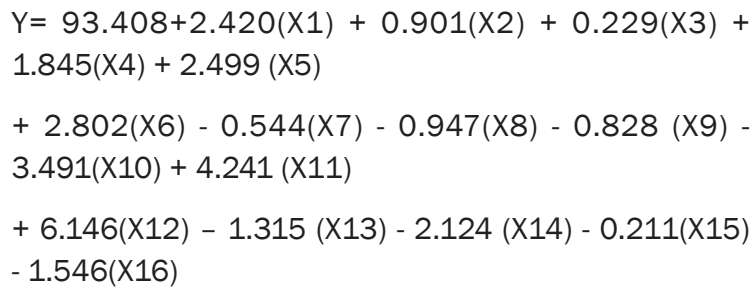

From the results, it could be observed that the value of regression co-efficient for the variables group communication (X11) and group leadership (X12) were found to have positive and significant relationship with group performance of tribal FIGs at one per cent level of probability and variables like age (X1), farm size (X5) and farming experience (X6) were found to have positive and significant relationship at five per cent level of probability. This suggested that a unit increase in age, farm size, farming experience, group communication and group leadership would increase the group performance of tribal FIGs by 2.420, 2.499, 2.802, 4.241 and 6.146 units, respectively. Hence, it may be concluded that age, farm size, farming experience, group communication and group leadership of the respondents were the very important variables contributing to the variation in group performance of tribal FIGs.

Farm size had a significant and positive relationship with group performance; thus tribal farmers with more area under cultivation were involved in group activities for maximizing their yield and income therefore, it may lead to increased group performance. Tribal farmers who had experienced in life, as well as farming, faced many different situations. Therefore, they would think critically in all aspects and work cooperatively to contribute to the group performance of tribal FIGs. Hence, age and farming experience were found as very much essential variables for group performance of tribal FIGs. It was witnessed that group communication was essential for group performance of tribal FIGs and thus, when all the activities were communicated among members of tribal FIGs they would actively work for the welfare of group and it may lead to an increased group performance of tribal FIGs.

Group leadership is the ability of leader of tribal FIGs to regulate, monitor group activities and also

107 | 10-12 | 
to influence other members towards its goal and enable the members of tribal FIGs to work with cooperation in spite of cultural differences.

The results also showed that the informationseeking behavior (X10) was found to be negative and significant at five per cent level of probability. This suggested that a unit increase in informationseeking behavior would decrease the group performance of tribal FIGs by 3.491 units. The present findings are in line with Naveenkumar and Radhakrishnan (2017).

\section{CONCLUSION}

Group-related variables such as group communication, group leadership and group cohesiveness were positively associated with group performance of tribal FIGs and variables viz., age, farm size, farming experience, group communication and group leadership were positively contributed to group performance of tribal FIGs. The findings of the study also revealed that members of tribal FIGs admitted that FIG had medium level of group performance of tribal FIGs. It could be concluded that communication, leadership and cohesiveness among the members are essential for group performance of tribal FIGs. To improve the effectiveness of tribal FIGs, measures should be taken to increase the level of group communication, group leadership and group cohesiveness. This can be increased through organizing regular meetings for members, proper selection of leaders and making the members to understand the importance of group action.

\section{REFERENCES}

Catalyst Management Services. 2009. Impact Assessment of Agriculture Interventions in Tribal Areas in Madhya Pradesh., Bhopal. Catalyst Management Services.

Chandravadia, K. M., Bariya and S. Kumbhani. 2018. Socio-economic profile of Tribal Farm women and its relationship towards involvement in Agriculture Practices in Chhotaudepur District of Gujarat State. Journal of Krishi Vigyan., 7: 139-143.

Department of Agriculture \& Cooperation. 2013. Policy and Process Guidelines for Farmer Producer Organizations. Ministry of Agriculture, Government of India.

Jona, C.N. and M.N. Nghixulifwa. 2018. Farmers involvement in farmer-based organization and perceived challenges: a case of Oshikoto region, Namibia. International Journal of Agricultural Extension., 6 (2): 61-69 (2018).
Mathuabirami, V., Kalaivani, S., Premavathi, R and Radha, M. 2020. Analysis on Effectiveness of Tribal Farmer Interest Groups (FIGs) in Tamil Nadu International Journal of Agricultural Science and Research., 10 (4): 169-174.

Mathuabirami, V and Kalaivani, S.2020. An Analytical Study on Relationship of Profile Characteristics with Effectiveness of Tribal FIGs in Tamil Nadu. Madras Agricultural Journal., 107(4-6): 216-219.

Mooventhan, P., K. Kadian., R. Senthilkumar and C. Karpagam.2015. Socio-Economic Profiling of Tribal Dairy Farmers in Northern Hills Zone of Chhattisgarh. Journal of Extension Education., 27 (3).

Naveen Kumar, M. and T. Rathakrishnan.2017. A Study on Relationship of Characteristics and Performance of Guava Farmer Interest Groups in Tamil Nadu. Madras Agricultural Journal., 104(7-9): 261-264

Naveen kumar, M. and T. Radhakrishnan. 2017. Performance of a Farmer Interest Group in Tamil Nadu. Journal of Extension Education., 28 (4): 5775-5779.

Pandey, D.K. and H. De.2015 Entrepreneurial behaviour of tribal fish farmers in Tripura, north-east India. Indian Journal of Fisheries., 62 (1): 149-152.

Patil Suresh, S., G. M. Hiremath and G. B. Lokesh. 2014. Economic Sustainability through Farmers Interest Groups and their Linkage with Institutional Agencies-An Evidence from Karnataka. Agricultural Economics Research Review., 27: (347-2016-17143), 141-146

Satish, K. D., Ritesh., Shobha and K. Sujeet. 2018. SocioEconomic Profile of Tribal Dairy Farmers in Godda of Jharkhand " International Journal of Current Microbiology and Applied Sciences., 7: 2727-2733.

Sharma, J., P. Singh., and R. Padaria. 2011. Social Processes and People's Participation in Watershed Development. Journal of Community Mobilization and Sustainable Development., 6 (2): 168-173

Shepherd, A. 2007. Approaches to linking producers to markets. Occasional paper, Agricultural Management, Marketing and Finance., Food \& Agriculture Org. 13.

Singh Katar and R. Srinivasan. 1998. Role of farmers' organization in the context of new economic policy with particular reference to agriculture marketing and agro-processing. Indian J. Agril. Mktg., 161-164. 